\title{
Sclerosing pneumocytoma accompanied with dilated air-containing space
}

\author{
Kengo Nishino, Kesato Iguchi, Norio Takayashiki, Hiroaki Satoh
}

Mito Medical Center, University of Tsukuba, Mito, Japan

Sclerosing pneumocytomas are one of the most common benign lung tumors. Although rare [1-4], some of them can be accompanied by dilated air-containing space.

A 61-year-old woman was referred to our hospital because of a nodule in the left lung detected in a chest radiograph mass screening program (Figure 1A). Chest computed tomography (CT) showed a well demarcated nodule with a peritumoral air-lucent zone in the lower left lobe. In chest radiograph taken at another medical institution 7 years ago, a nodule was detected in the left lung, which was diagnosed as a sclerosing pneumocytoma (Figure 1B). However, the patient did not wish further evaluation because she was asymptomatic. Eighteen months after the first visit to our hospital, she came to our institution because of hemoptysis. Chest CT taken at that time confirmed that the nodule with peritumoral air-lucent zone increased by a maximum diameter of $7 \mathrm{~mm}$ at this interval (Figure 1C). With the advent of hemoptysis, surgical resection was performed. The patient was pathologically diagnosed as having a sclerosing pneumocytoma, and the presence of a dilated air-containing space corresponding to the peritumoral air-lucent zone seen on CT was pathologically confirmed. When calculated using Schwartz's formula, the tumor doubling time was 5.9 years, and its onset was estimated to be more than 10 years ago.

Pulmonary sclerosing pneumocytoma is one of the most common benign tumors of the lung. It is pathologically composed of several components such as cartilage, connective tissue, muscle, fat, and bone. The tumor usually occurs at the age of 40 and 50. The majority of lung sclerosing pneumocytomas develop in the periphery of the lung [1-5]. They are typically well-circumscribed nodules or masses with either smooth or lobulated margins. Although rare, however, some of the patients with sclerosing hemangioma could be accompanied by dilated air-containing space [1-4]. Patients with this tumor are usually asymptomatic and they are found incidentally when imaging the chest for other reasons. However, it can occasionally present with hemoptysis, bronchial obstruction, and cough. It has been estimated that these benign tumors grow very slowly, however, to the best of our knowledge, there has been no report to reveal their volume doubling time.
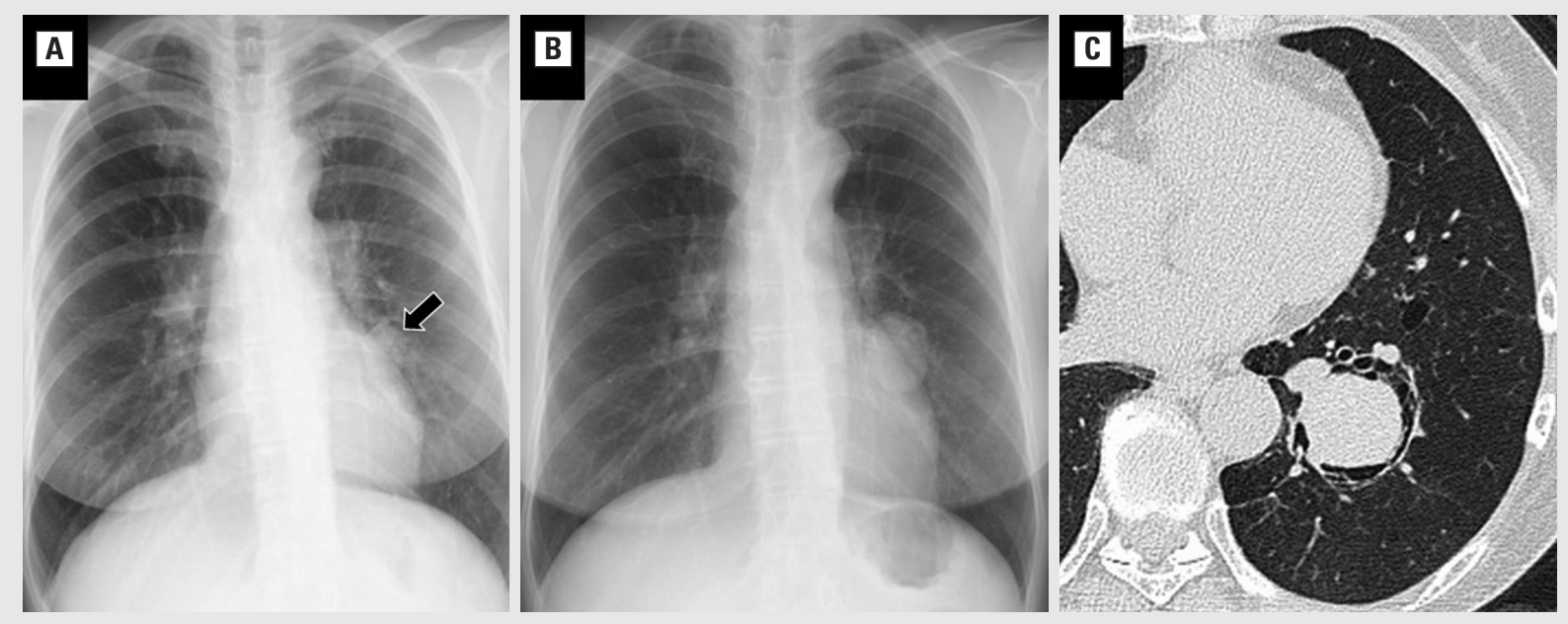

Figure 1. A nodule in the left lung (arrow) in plain chest radiograph taken 7 years ago (A), and that taken at the first visit to our hospital (B). The nodule in chest computed tomo taken 18 months after the first visit (C)

Address for correspondence: Hiroaki Satoh, Mito Medical Center, University of Tsukuba, Miya-machi 3-2-7, 3100015 Mito, Japan; e-mail: hirosato@md.tsukuba.ac.jp DOI: 10.5603/ARM.a2021.0061 | Received: 02.02.2021 | Copyright (C 2021 PTChP | ISSN 2451-4934 | e-ISSN 2543-6031

This article is available in open access under Creative Common Attribution-Non-Commercial-No Derivatives 4.0 International (CC BY-NC-ND 4.0) license, allowing to download articles and share them with others as long as they credit the authors and the publisher, but without permission to change them in any way or use them commercially. 
No studies have examined the volume doubling time of this tumor with dilated air-containing space. Although rare, sclerosing pneumocytoma is showing CT images similar to "halo sign" and 'meniscus sign'that have been observed in our patient too. There have been reports suggesting the involvement of tumor-related bleeding in the pathological findings of such signs and space formation around the tumor. The current report presents the natural history of such a type of lung sclerosing pneumocytoma that presented as a slow-growing mass, which was determined by calculating its doubling time and volume changes.

This study was approved by the institutional ethics committee in our Hospital. Written comprehensive informed consent at the time of admission for obtaining pathological specimens was acquired from the patient.

\section{Conflict of interest}

No conflict of interest was declared by the authors.

\section{REFERENCES:}

1. Sagara Y, Hayashi K, Shiraishi Y, et al. The pulmonary air meniscus sign in a case of sclerosing pneumocytoma. Nihon Kyobu Shikkan Gakkai Zasshi 1994; 32:774-7. Nihon Kyobu Shikkan Gakkai Zasshi. 1994; 32(8): 774-777, indexed in Pubmed: 7807757.

2. Matsuyama W, Hirotsu Y, Mizoguchi A, et al. Pulmonary sclerosing hemangioma with specific CT findings. Nihon Kokyuki Gakkai Zasshi. 1998; 36(6): 564-567, indexed in Pubmed: 9754011.

3. Nam JiE, Ryu YH, Cho SHo, et al. Air-trapping zone surrounding sclerosing hemangioma of the lung. J Comput Assist Tomogr. 2002; 26(3): 358-361, doi: 10.1097/00004728-200205000-00007, indexed in Pubmed: 12016362.

4. Bae K, Song DH, Jeon KN, et al. Pulmonary sclerosing pneumocytoma presenting a peritumoral halo and an intervening lucent zone on computed tomography: Radiology-pathology correlation. Thorac Cancer. 2019; 10(5): 1295-1296, doi: 10.1111/1759-7714.13069, indexed in Pubmed: 30964602.

5. Pal P, Chetty R. Multiple sclerosing pneumocytomas: a review. J Clin Pathol. 2020; 73(9): 531-534, doi: 10.1136/jclinpath-2020-206501, indexed in Pubmed: $\underline{32317291}$. 